\title{
A description of the eggs of seven species of Noctuidae (Lepidoptera) commonly transported by plant trade to the UK, and their separation using stereomicroscopy and scanning electron microscopy
}

\author{
Anastasia Korycinska
}

\begin{abstract}
Eggs of seven economically important noctuids commonly transported in plant trade, three of quarantine plant health significance in Europe, are described and illustrated using stereomicroscopy and scanning electron microscopy. Autographa gamma (Linnaeus), Helicoverpa armigera (Hübner), Lacanobia oleracea (Linnaeus), Mamestra brassicae (Linnaeus), Spodoptera exigua (Hübner), S. littoralis (Boisduval) and S. litura (Fabricius) could be separated using external morphological characters on the chorion of the eggs, enabling early identification of quarantine pest species. Keys to distinguish the eggs of the seven species are provided.

Anastasia Korycinska, The Food and Environment Research Agency, Sand Hutton, York YO41 1LZ, United Kingdom. anastasia.korycinska@fera.gsi.gov.uk
\end{abstract}

\section{Introduction}

Immature stages of Lepidoptera, many from the family Noctuidae, are inadvertently, and frequently, transported during international plant trade (Malumphy \& Robinson 2002). While the adults of most species are well described, there is often little information available for other life stages. Lepidoptera intercepted on plant material by plant health authorities are almost exclusively immature life stages, i.e., larvae or eggs, and must be reared to late instar larvae or adults for species identification, and this can take weeks, or even months. However, it is not practical to hold plant material for this length of time at ports of entry until a final identification can be made. To enable a National Plant Protection Organisation (NPPO) to decide upon an appropriate course of action within a realistic timescale, accurate and timely identification of all immature life stages is necessary. Morphological screening of eggs can be carried out using stereomicroscopy very rapidly (within half a day), with little or no specimen preparation required.
The eggs can subsequently be prepared for scanning electron microscope (SEM) micrographs, reared to confirm the identification, or sent for molecular analysis, depending on the rapid screening results and the individual requirements of the import sample.

Eggs are often less obvious during pre-import inspections than the larger and active later life stages, and so are often the life stage encountered during plant health border inspections. There have been a number of previous studies on noctuid egg morphology using both light microscopy and SEM micrographs, and these have established morphological characters that are of potential diagnostic significance. A number of previous studies described the eggs of a single species (such as for Hyponeuma taltula (Schaus, 1904) (Zenker et al. 2007a); Spodoptera cosmioides (Walker, 1858) (Zenker et al. 2007b); and S. eridania (Stoll, 1781) (Valverde 2007)). The eggs of multiple noctuid species have been studied in North and South America; these studies range from illustrated descriptions (e.g., Peterson 1964; Salkeld 
1984), to more comparative work (such as Hudson 1973; Olivares \& Angulo 2004; Olivares et al. 2005; Andaur-Arenas \& Olivares 2009). Collectively, the previous work enables the eggs of selected species and genera of Noctuidae from America to be identified, many to species. However, eggs from noctuid species in the Old World have been studied less intensively, and eggs from these regions cannot be identified using New World sources.

Seven species of noctuid were selected for the current study: all are polyphagous pest species and they include three species listed in the legislation of the European Union Plant Health Directive (2000/29/EC, as amended), Helicoverpa armigera (Hübner, 1827), Spodoptera littoralis (Boisduval, 1833) and S. litura (Fabricius, 1775). The other four species (S. exigua (Hübner, [1808]), Mamestra brassicae (Linnaeus, 1758), Lacanobia oleracea (Linnaeus, 1758) and Autographa gamma (Linnaeus, 1758)) are also frequently found on plants moving in trade by the plant health authorities of England and Wales (Food and Environment Research Agency (Fera), unpublished data). There is thus a quarantine need to distinguish these species, listed and unlisted, from each other as quickly and accurately as possible.

Stand alone descriptions of the eggs based on SEM micrographs are available for $S$. littoralis (Fehrenbach et al. 1987), S. exigua (as S. exiqua; Skudlik et al. 2005) and M. brassicae (Sannino \& Espinosa 1999), but not for the other four species studied here, although Matthews (1999) did provide an overall SEM micrograph of an egg of $H$. armigera. Döring (1955) provided a key, general descriptions and diagrams of the eggs of a number of noctuid species, including A. gamma, L. oleracea and M. brassicae, but was restricted to light microscopy.

The aim of this study therefore was to examine and describe the eggs of all seven species in order to produce a practical means of distinguishing them within a UK plant quarantine context. The eggs were described and illustrated from the seven species using both stereomicroscopy and SEM micrographs. Three of the species have SEM micrographs provided for the first time, and comparative characters between all seven species are presented and discussed. Keys are provided to distinguish the eggs of all seven species studied here, through stereomicroscopy and using SEM micrographs.

\section{Materials and methods \\ Insects}

Supplies of eggs were obtained from the sources listed in Table 1. The identity of all the material used in the study was confirmed by identification of adults reared from the source material, by comparison with validated reference specimens and with published morphological descriptions (Hardwick 1965; Mochida 1973; Skinner 1984; Waring $\&$ Townsend 2003). All eggs were preserved by initially placing them in $30 \%$ ethanol in labelled $1.5 \mathrm{ml}$ microtubes for a minimum of 48 hours and then transferring them to $70 \%$ ethanol and storing them at $4^{\circ} \mathrm{C}$. Two of the populations were sourced from quarantine interceptions with a limited number of adult females available: $S$. litura from India (one female); and $H$. armigera from Egypt (two females). For all the other populations, a number of moths laid eggs in culture on the leaves of Brassica rapa L. (Pekinensis group) plants, and eggs were preserved from a minimum of five different batches, or from different areas of the cage if the eggs were laid singly.

\section{Terminology}

Egg terminology follows Peterson (1964) and Döring (1955). The major terminology used here is defined

Table 1. Sources of eggs and the number from each species viewed (+: some eggs partially collapsed under vacuum, although features remained useable).

\begin{tabular}{|c|c|c|c|c|}
\hline \multirow[t]{2}{*}{ Species } & \multirow[t]{2}{*}{ Source } & \multirow[t]{2}{*}{ Geographical origin } & \multicolumn{2}{|c|}{ Number of eggs viewed } \\
\hline & & & Stereomicroscope & SEM \\
\hline Autographa gamma & CEH, Oxford, UK & Not known & 20 & $12+$ \\
\hline Helicoverpa armigera & CEH, Oxford, UK & Not known & 10 & - \\
\hline H. armigera & PHSI quarantine interception on Pisum sativum & Egypt & 20 & 10 \\
\hline Lacanobia oleracea & Fera, UK & Jersey & 20 & $13+$ \\
\hline Mamestra brassicae & Fera, UK & UK & 20 & $10+$ \\
\hline Spodoptera exigua & CEH, Oxford, UK & Not known & 20 & $15+$ \\
\hline Spodoptera littoralis & Fera, UK (culture originally from the University of Durham) & Not known & 20 & $20+$ \\
\hline Spodoptera litura & PHSI quarantine interception on Ocimum americanum & Thailand & 20 & 10 \\
\hline S. litura & PHSI quarantine interception on Momordica sp. & India & 15 & $12+$ \\
\hline S. litura & PHSI quarantine sample on Begonia hybrids & Not known & 20 & $7+$ \\
\hline
\end{tabular}

Abbreviations: CEH, Centre of Ecology and Hydrology; PHSI, Plant Health and Seeds Inspectorate (England and Wales); Fera, The Food and Environment Research Agency. 


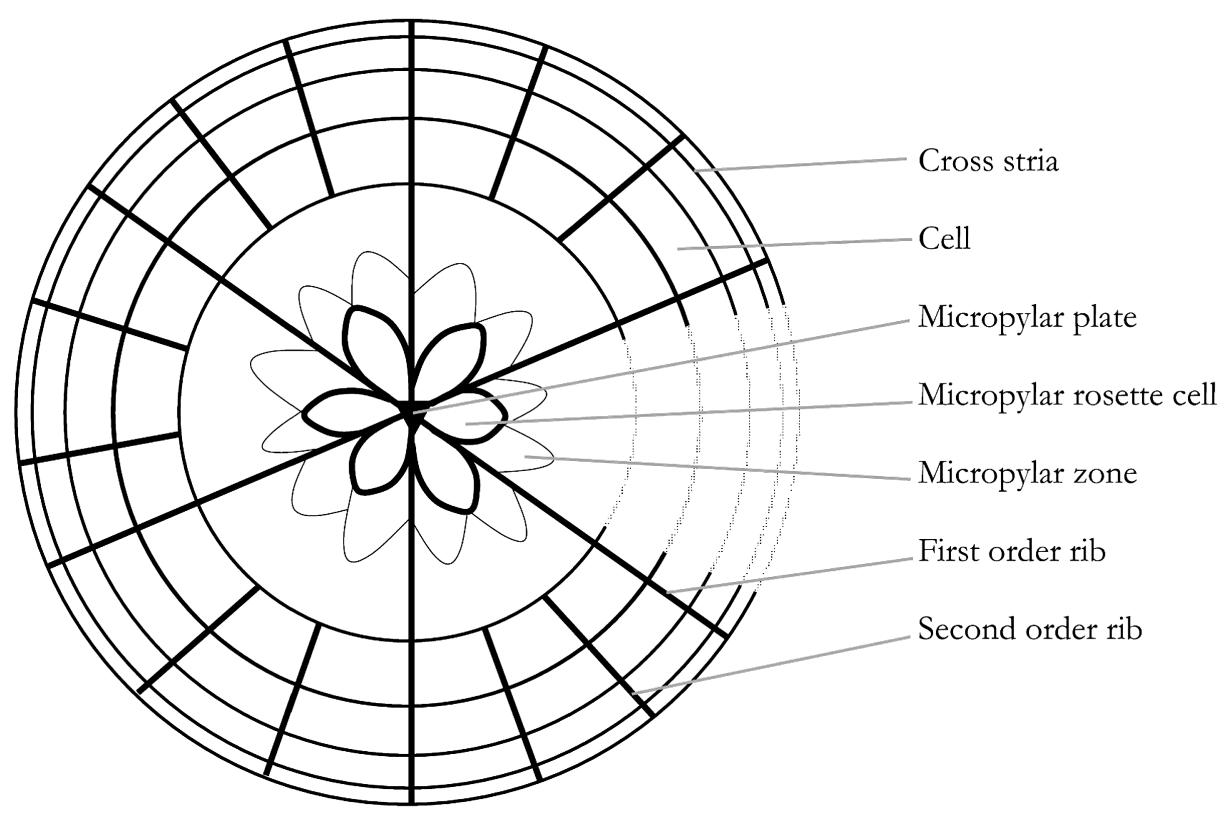

Fig. 1. Generalised diagram of the surface features of an egg from the family Noctuidae in dorsal view. Terminology follows Peterson (1964) and Döring (1955).

as follows. The micropylar plate is a small flattened area on the dorsal pole of the egg. The micropylar rosette is the region of cells immediately surrounding the micropylar plate. The micropylar zone is a region of cells, usually ill defined or very irregular, immediately surrounding the micropylar rosette (the division between this region and the ribs and cross striae is not always clear). Ribs are radial structures: first-order ribs reach the micropylar rosette while second-order ribs terminate before this region. Cross striae (singular stria) encircle the egg, usually more or less perpendicular to the ribs. A cell is any region bounded by raised sculpture: if no region is specified, a cell is bounded by ribs and cross striae. Figure 1 labels the features used in this study on a generalised diagram of a noctuid egg in dorsal view.

\section{Morphological examination: stereomicroscopy}

A minimum of 20 preserved eggs for each species were viewed under a Leica WILD M10 stereomicroscope ( $80 \times$ magnification). The eggs were briefly airdried, then viewed using slightly oblique top lighting. For eggs with only faint surface sculpture, the tip of a fine permanent ink felt tip pen was touched to the top of the egg briefly to create a greater contrast.

The eggs were assessed for the following variable characters: whether the eggs were laid singly or in groups; if they were covered in hairs or were naked; the overall shape of the egg; the form of the cells in the micropylar zone; the comparative heights of the ribs and cross striae; the comparative heights of the micropylar rosette cells and other cells on the egg surface; and the colouration of the egg.

\section{Morphological examination: scanning electron microscopy}

Preserved eggs were prepared for scanning electron microscopy by air drying them briefly and removing surface debris, then mounting on an SEM stub using double-sided carbon tape. No further treatment was performed before sputter coating with gold. The stubs were examined with the SEM (Cambridge stereoscan 250 Mark 2, fitted with a lanthium hexaboride emission head), using a range of $3-10 \mathrm{kV}$, and magnifications of up to $1000 \times$. Images were captured of all eggs that did not collapse in the vacuum, with a minimum of ten different eggs for each species studied (Table 1). Additionally, images were taken of regions of collapsed eggs if these regions were not deformed by the collapse.

The SEM images of the overall eggs and closeup views of the micropylar regions were examined for polymorphic characters. The characters assessed were: the number of micropyle rosette cells; the form of the micropylar rosette cells; the form of the cells in the micropylar zone; the number of first- and second-order ribs where it was possible to differentiate between the types, otherwise the total number 
of ribs; the relative heights of the ribs and cross striae; whether the height of the ribs was constant; presence or absence of internal sculpturing in cells, and the form of any such sculpture (carinae are elongated structures or ridges; tubercles are rounded structures which are never elongated); and the shape of the cells towards the longitudinal midline of the egg where the sculpturing fades into the smooth ventral surface of the egg.

\section{A key to distinguish the eggs of seven species of Noctuidae using stereomicroscopy $(80 \times$ magnification)}

1. Eggs laid singly, or in loose clusters of usually no more than five ............. 2

- Eggs laid in more or less well arranged batches of more than five eggs, usually more than ten..................... 3

2. Egg about as high as wide; a smooth area surrounds the micropylar rosette, at least as wide as the micropylar rosette; the micropylar rosette clearly raised above, and differentiated from, surrounding cells; 1519 micropylar rosette cells; $28-33$ ribs in total ............... Helicoverpa armigera

- Egg wider than high; small cells surround the micropylar rosette, with any smooth area much narrower than the micropylar rosette; micropylar rosette neither raised above nor markedly different from surrounding cells; 5-8 micropylar rosette cells; $26-38$ ribs in total . ............ .............. Autographa gamma (part)

3. Egg batch with at least some hairs on or around it and often densely covered; may be laid in two or more layers .......... 4

- Egg batch never with associated hairs; usually laid in a single layer . ............ 5

4. Micropylar rosette barely visible and much less prominent than other cells on the egg; 6-11 micropylar rosette cells; 40-60 ribs in total ....................... ..... Spodoptera littoralis or Spodoptera litura

- Micropylar rosette clearly visible, subequal in strength to other cells on the egg; 11-15 micropylar rosette cells; $41-50$ ribs in total ................... Spodoptera exigua

5. Unicolourous, usually white, cream or light green.................... 6

- Bicolourous: cream with a red/brown ring and dorsal dot; 11-14 micropylar rosette cells; 32-43 ribs in total ............. ........Mamestra brassicae (live mature egg)
6. Micropylar rosette cells clearly differentiated from cells in the micropylar zone ..... 7

- Micropylar rosette cells not clearly differentiated from cells in the micropylar zone; ribs much stronger than cross striae; 5-8 micropylar rosette cells; 26-38 ribs in total..............Autographa gamma (part)

7. Ribs stronger than the cross striae; where the second-order ribs arise, cross striae very inconspicuous, or not visible; 11-14 micropylar rosette cells; 32-43 ribs in total Mamestra brassicae (newly laid/preserved egg)

- Ribs and cross striae subequal in strength; where the second-order ribs arise, cross striae apparent; 12-16 micropylar rosette cells; 38-47 ribs in total . . Lacanobia oleracea

\section{A key to distinguish the eggs of seven species of Noctuidae using scanning electron microscopy}

1. Micropylar rosette cells entirely enclosed by a raised boundary ridge, except for a very narrow area at the micropylar plate .... 2

- Micropylar rosette cells open, with internal carinae that do not meet the outer borders of the rosette cells; 5-8 cells in the micropylar rosette; $26-38$ ribs in total...... ......................

2. First-order ribs much the same height throughout their length, never raised markedly above the surface of the egg at the micropylar zone.................. 3

- First-order ribs increase markedly in height between the area where the second-order ribs terminate and the micropylar zone; cross-striae not clearly marked; $15-19$ cells in the micropylar rosette; $28-33$ ribs in total ............... Helicoverpa armigera

3. Micropylar rosette cells never more strongly marked than the cells in the micropylar zone; cross striae and ribs subequal in strength .................... 4

- Micropylar rosette cells much more strongly marked than the cells in the micropylar zone; cross striae less prominent than the ribs; $12-14$ cells in the micropylar rosette; 32-43 ribs in total....... Mamestra brassicae

4. Micropylar rosette cell boundaries subequal in strength to cells in the micropylar zone; micropylar rosette cells with clearly raised tubercles; cross striae do not form a regular grid with the ribs; $11-15$ cells in the micropylar rosette; $41-50$ ribs in total ................. Spodoptera exigua 
- Micropylar rosette cells less strongly marked than other cells, though cells in the micropylar zone may also be poorly marked; any tubercles in the micropylar rosette cells not markedly raised ......... 5

5. Micropylar rosette cells subequal in strength to cells in the micropylar zone, both less differentiated than other cells; 11 or fewer cells in the micropylar rosette.....6 6

- Micropylar zone cells stronger than micropylar rosette cells; micropylar rosette cells with very faint tubercles; cross striae are very strongly marked; most cells are square or rectangular; $12-16$ cells in the micropylar rosette, though they are poorly marked and difficult to enumerate; 38-47 ribs in total ............ Lacanobia oleracea

6. On the lateral side of the egg, the last visible cells mostly quadrilateral and regular; classification of cell boundaries as ribs and striae is straightforward; 8-11 cells in the micropylar rosette; $40-52$ ribs in total ... .................... Spodoptera litura

- On the lateral side of the egg, the last visible cells not usually regular quadrilaterals, instead consisting of pentagons and hexagons; cell boundaries sometimes difficult to classify as ribs and striae; 7-8 cells in the micropylar rosette; $45-60$ ribs in total ................ Spodoptera littoralis

\section{Results \\ Morphological descriptions Autographa gamma}

Habitus. The eggs are laid either singly or in large groups, and are not covered in hairs or scales (Fig. 2). They are off-white in colour and broadly hemispherical, wider than high.

Stereomicroscopy. There is no clear central rosette of cells, but instead an ill-defined circular area of small cells. If a smooth flat area is visible between the ribs and the micropylar rosette, then this is much narrower than the radius of the rosette. The ribs reach the outer edge of this group of cells, and are almost constant in height. The ribs are much stronger in appearance than the cross striae.

Scanning electron micrographs. The micropylar rosette has 5-8 cells, none of which is closed. Instead, each possesses internal carinae that do not connect with the outer borders of the rosette within each cell (Fig. 3). There are 2-4 carinae in each cell, and the outer carinae usually shadow the area where a cell boundary would be found. The micropylar zone has cells similar in size and shape to those in the rosette, and at least the inner row of cells in this zone also has carinae. The cells gradually increase in size as the distance from the micropylar plate increases. The ribs all terminate at or before the outer border of the micropylar zone, and there are second-order ribs that are not connected to the micropylar zone at all. There are 13-18 ribs that reach the micropylar zone, and 13-17 secondorder ribs (Fig. 4). Cross striae are less prominent than the main ribs and no strongly marked cells are present below the area where the second-order ribs arise.

\section{Helicoverpa armigera}

Habitus. The eggs are laid singly, or in clusters of less than five eggs, and are not covered in hairs or scales. They are unicolourous white or green and broadly spherical in shape, about equal in height and width (Fig. 5).

Stereomicroscopy. There is a smooth flattened ring around the rosette of cells, which is broader than the radius of the micropylar rosette. The micropylar rosette is distinctly raised above this flattened area. With the correct angle of lighting, very faint lines can usually be seen that connect at least one of the ribs to the central rosette of cells. The ribs come to a prominent end some distance short of the micropylar region, with a clear, raised, end-point to each rib. The cross striae are less prominent than the ribs.

Scanning electron micrographs. The micropylar rosette cells are clearly marked, and have 15-19 cells, almost completely closed except for the short margin at the micropylar plate (Fig. 6). There are no tubercles in the rosette cells. The micropylar zone has no clearly marked cross striae. Some eggs have clear lines extending from the ends of the ribs into the micropylar zone, but others show no lines at all. The ribs all terminate abruptly at the micropylar zone, the first-order ribs having become raised noticeably above the surface of the egg into carinae, this occurring after the point where the second-order ribs end (Fig. 7). The second-order ribs do not end in a raised ridge above the surface of the egg. There are 13-15 first-order ribs, and 15-18 second-order ribs. The cross striae are less prominent than the ribs, and form a regular grid of cells on the surface of the egg. 


\section{Lacanobia oleracea}

Habitus. The eggs are laid in clusters, usually in a single layer, and are not covered in hairs or scales (Fig. 8). They are hemispherical, usually slightly wider than high, and typically pale green in colour, with no distinctly flattened top.

Stereomicroscopy. The micropylar rosette is present as a small flattened area in the centre of the egg. The micropylar zone is not clearly distinguished from the region with ribs and cross striae. The ribs and cross striae are subequal in strength, and where the second-order ribs arise, the cross striae are already very evident. The cross striae form a system of circles, increasing in diameter as they approach the lateral side of the egg. The overall impression is of a grid system over the surface of the egg, the cells getting more regular and square as the distance from the micropyle increases.

Scanning electron micrographs. The micropylar rosette cells are less defined than all of the other cells on the egg. The rosette cells are almost completely closed, only open for a very short distance at the micropylar plate. There are $12-16$ cells in the rosette, though the cell borders can be poorly delineated, and thus the cells can be difficult to count accurately, even under the SEM (Fig. 9). There are very faint tubercles in the rosette cells. The micropylar zone is not clearly differentiated from the more lateral regions of the egg, though the cells in the micropylar zone are more irregular shapes, with fewer quadrilaterals among them. There are 15-17 first-order ribs, and 23-30 secondorder ribs. The cross striae are subequal in strength to the ribs. Cells are strongly marked and nearly always rectangular or square, with exceptions at the points where a second-order rib starts, where one cell will be pentagonal or triangular as the ribs diverge (Fig. 10).

\section{Mamestra brassicae}

Habitus. The hemispherical eggs are laid in a flat cluster, usually in a single layer, and are not covered in hairs or scales. The eggs are usually about equal in height and width and smoothly rounded. Newly laid eggs are uniformly green-white in colour, but after approximately one day, they develop red-brown markings on a cream base colour. The markings consist of an irregular dot over the micropylar region and a ring around the centre of the egg (Fig. 11). The markings are very variable, even within the same egg batch.

Stereomicroscopy. A clear rosette of cells is visible around the micropylar plate, and a much less distinct second row of cells surrounds this. The ribs are stronger than the cross striae. In the region where the second-order ribs arise the cross striae are very inconspicuous, or not visible at all.

Scanning electron micrographs. The micropylar rosette is one of the more prominent structures on the surface of the egg. There are 12-14 cells, all closed except for a narrow opening at the micropylar plate (Fig. 12). There are no tubercles in the rosette cells. The micropylar zone forms an ill-defined secondary rosette of cells, much less prominent than the micropylar rosette. The first-order ribs become less sharply defined and lower as they extend beyond the end of the second-order ribs and towards the micropylar rosette (Fig. 13). There are 18-21 first-order ribs, and 18-22 second-order ribs. The ribs are always more prominent than the cross striae, which are faintly visible before the start of the second-order ribs, and become slightly more prominent further down the egg.

\section{Spodoptera exigua}

Habitus. The eggs are laid in a mass, often consisting of several layers of eggs, and are covered in hairs from the moth's abdomen (Fig. 14). The eggs are slightly flattened dorsally, distinctly wider than high, and are off-white in colouration, though the surrounding hairs can give the impression of a yellow hue.

Stereomicroscopy. The micropylar rosette is clearly marked, and it is usually possible to count the individual cells. The rosette of cells is as strongly defined as the other cells on the egg surface. All the ribs and cross striae are subequal in strength, and the cross striae do not form a grid pattern, instead meeting the longitudinal ribs at a variety of angles.

Scanning electron micrographs. The micropylar rosette has 11-15 cells. Each cell is almost closed, with a small opening at the micropylar plate. The rosette cells have sculpturing inside each cell that consists of raised tubercles (Fig. 15). All the cells in the egg, including the rosette cells, are subequal in strength. The row of cells in the micropylar zone immediately surrounding the rosette is mostly elongated. The ribs are not easy to define as first-order and second-order, as they diverge, converge and on occasion may even be classed as cross striae (Fig. 16). Thus, it is also difficult to accurately count the number of ribs, and the range of 41-50 should be regarded with some caution. The ribs were counted at a level about halfway between the end of the micropylar zone and the point where the cells disappear at the lower half of the egg. Cross striae are not easily differentiated from ribs. 

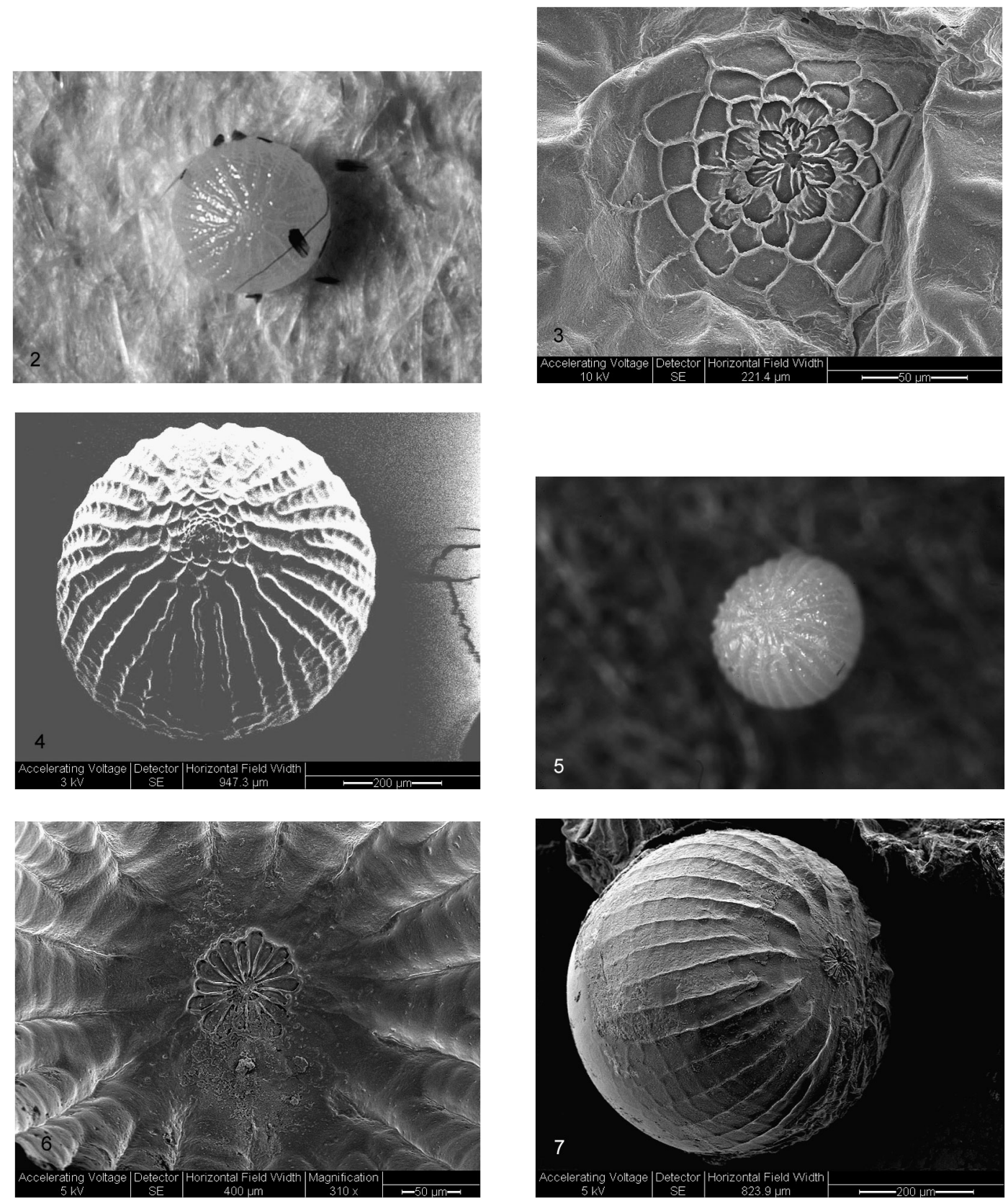

Figs 2-7. Images of noctuid eggs: habitus, SEM image of the micropylar region, overall SEM. 2-4, Autographa gamma. 5-7, Helicoverpa armigera.

\section{Spodoptera littoralis}

Habitus. The eggs are laid in a mass, which may consist of several layers of eggs, and covered in hairs from the moth's abdomen (Fig. 17). They are overall slightly dorsally flattened in appearance, the flattened area extending beyond the micropylar region, and are distinctly wider than high. The eggs are off-white in colouration, though the surrounding hairs can give the impression of a yellow colour.

Stereomicroscopy. The rosette of cells around the micropyle is not clearly visible, being less strongly de- 

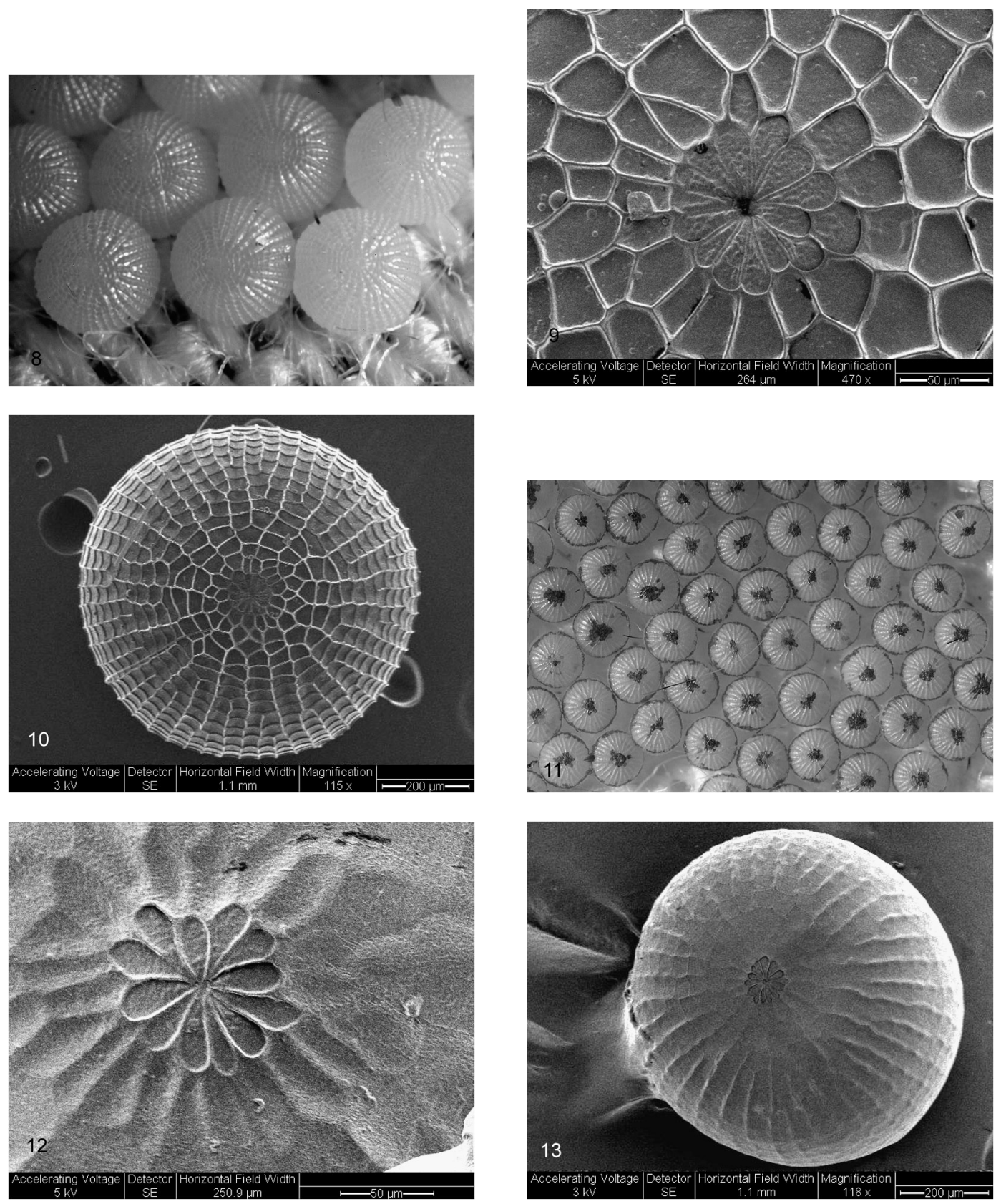

Figs 8-13. Images of noctuid eggs: habitus, SEM image of the micropylar region, overall SEM. 8-10, Lacanobia oleracea. 11-13, Mamestra brassicae.

fined than the other cells on the egg's surface. It is very difficult, or impossible, to count the individual cells in the rosette. All the ribs and cross striae are subequal in strength, and the cross striae are not regular, instead meeting the longitudinal ribs at a variety of angles.
Scanning electron micrographs. The micropylar rosette has 7-8 cells, almost fully closed and only open for a very short distance at the micropylar plate (Fig. 18). There are no tubercles in the rosette cells. The cells in the micropylar rosette and in the micropylar zone are less prominent than the 
remainder of the cells on the egg. Ribs are not easy to define as first-order and second-order, as they diverge, converge, and on occasion may be classed as cross striae. Thus, it is also difficult to accurately count the number of ribs, and the range of 4550 ribs given here should be regarded with some caution. The ribs were counted at a level about halfway between the end of the micropylar zone and the point where the cells disappear at the lower half of the egg. At the midline of the egg, the cells in the last two visible rows are mostly irregularly hexagonal or pentagonal in shape in the population studied, though occasional cells are rectangular. There are at most 4 rows of rectangular or square cells formed by the intersection of the main ribs and the cross striae, while the rest of the egg has cells that are not regular in shape, and that rarely form regular rows with fully encircling cross striae (Fig. 19).

\section{Spodoptera litura}

Habitus (Fig. 20) and stereomicroscopy. Similar to $S$. littoralis.

Scanning electron micrographs. The micropylar rosette has 8-11 cells, which are almost fully closed and only open for a very short distance at the micropylar plate (Fig. 21). However, only one egg (out of 29) had 11 cells in the micropylar rosette, with the range for the rest 8-9 cells. There are no tubercles in the rosette cells. The cells in the micropylar rosette and the micropylar zone are less prominent than the surrounding ribs. The ribs are difficult to classify as first- and second-order ribs, but they are mostly differentiated from the cross striae. In the population from Thailand, there were 40-45 ribs in total when counted at a level halfway between the micropylar plate and the point where the markings disappear. In the population from India, there were 47-52 ribs. The third population, of unknown origin, had 44-46 ribs. In all three populations studied, at the midline of the egg where the sculpturing starts to flatten and become smooth, the ribs and cross striae form relatively regular rectangular shapes, or at least quadrilaterals, right up to the point where cells are no longer distinguishable and the smooth egg base starts (Fig. 22). There are at least four rows of reasonably square or rectangular cells between the micropylar zone and the end of the sculpturing, though each cross stria may not fully encircle the egg and occasional cells are still irregular.

\section{Discussion}

Eggs from all seven noctuid species studied here could be successfully separated using surface morphology. SEM images were of sufficient resolution to enable the eggs of all seven species from the studied populations to be separated, including the closely related Spodoptera littoralis and S. litura. At the lower resolution provided by stereomicroscopy (which involves minimal sample preparation), the eggs of $A u$ tographa gamma, Helicoverpa armigera, the genus Spodoptera Guenée, 1852 (as represented by the 3 species studied), and Lacanobia oleracea/Mamestra brassicae could still be distinguished from each other. Spodoptera exigua eggs could be separated from the eggs of S. littoralis and S. litura, primarily by assessing the strength of the micropylar rosette cells in comparison to the cells on the rest of the egg. This character is best used with previous experience, or direct comparison of the eggs of $S$. exigua and one of the other two species of Spodoptera. The number of micropylar rosette cells may also be used to separate the three species in the populations studied, with $S$. exigua having more cells than the other two species, though 11 rosette cells have been recorded in all three species (Table 2). However, as all three Spodoptera species lay eggs in a mass, it is possible to examine several eggs and assess the range in number of micropylar rosette cells. The chorion can also be mounted on a slide and examined using compound microscopy to count the micropylar rosette cells accurately, though other regions of the egg may be distorted with this technique. The bicoloured mature eggs of $M$. brassicae were easily separated from the other species, but newly laid or preserved eggs (which are unicolourous) could be confused with $L$. oleracea eggs.

Autographa gamma was the only species examined here where the micropylar rosette cells were open, with no cell borders, and with longitudinal carinae present in both the micropylar rosette and the cells immediately surrounding it. However, this was the only species from the subfamily Plusiinae studied, and the characters given here may not rule out other genera or species in the subfamily. Previous work on A. gamma using light microscopy (Döring 1955 ) found a substantially higher number of firstorder ribs, but the increased resolution of the SEM may enable better distinction to be made between first and second order ribs. The total number of ribs reported by Döring (1955) was also higher than found here, and this may be due to variation between populations as other species also show some variation in the ranges of total numbers of ribs (Table 2).

The total number of ribs reported here for $\mathrm{He}$ licoverpa armigera is slightly higher than previous work, but the number quoted was counted from a published image of a single egg (Matthews 1999), and may have been miscounted. Helicoverpa armigera is unique among the species examined here in hav- 

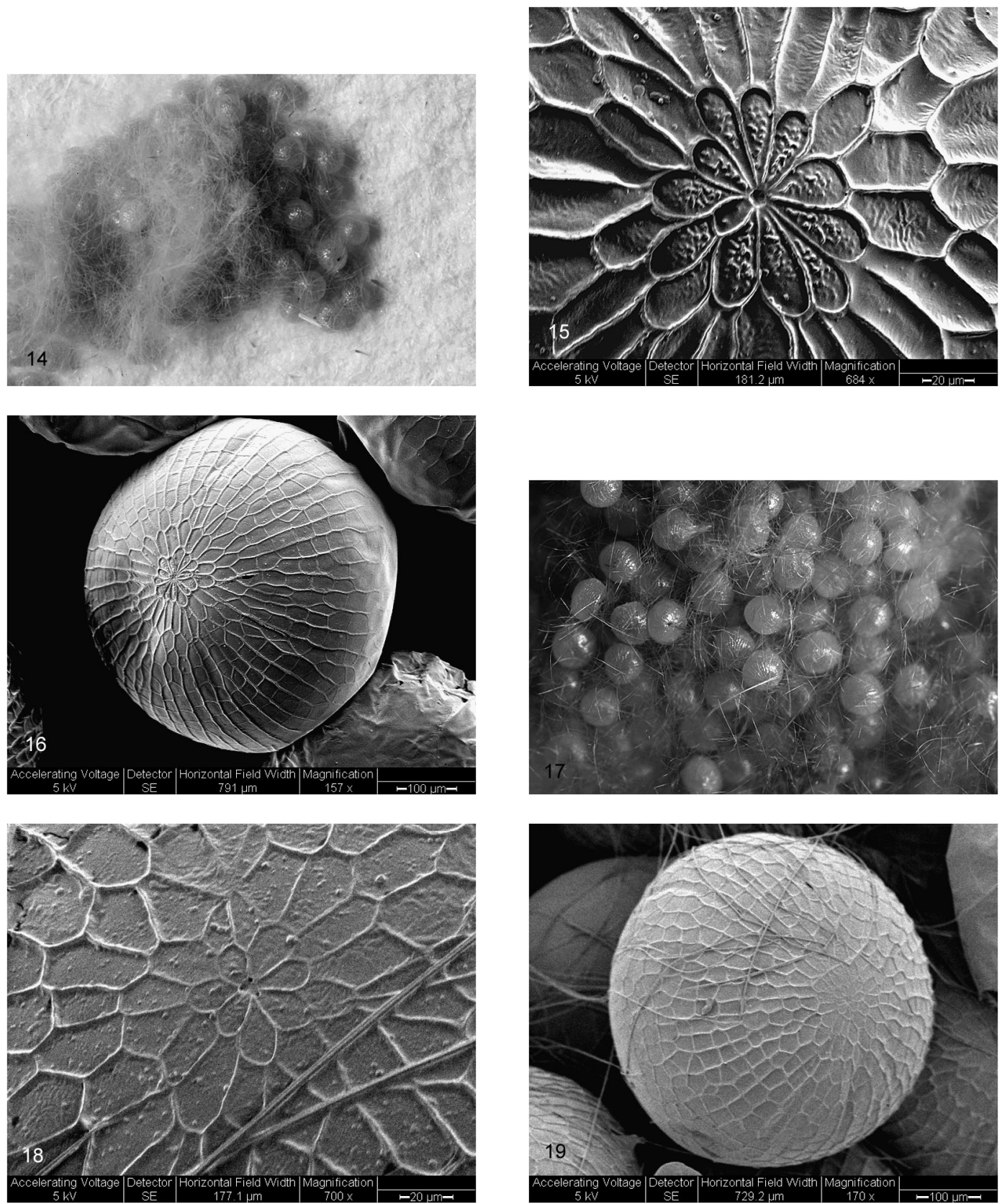

Figs 14-19. Images of Spodoptera (Noctuidae) eggs: habitus, SEM image of the micropylar region, overall SEM. 14-16, S. exigua. 17-19, S. littoralis.

ing the ends of the ribs increasing in height as they approach the micropylar region. However, this character is found in other species in the heliothine subfamily including H. zea (Boddie, 1850) and Heliothis virescens (Fabricius, 1777) (Bernhardt \& Philips 1985). Neunzig (1964) studied the eggs of H. zea and $H$. virescens, and concluded that the majority of the eggs of the two species could be separated from each other on the number of ribs and the form of the cells between them, but the range overlapped and some eggs could not be identified. A reliable method of separating the eggs of the two species was 

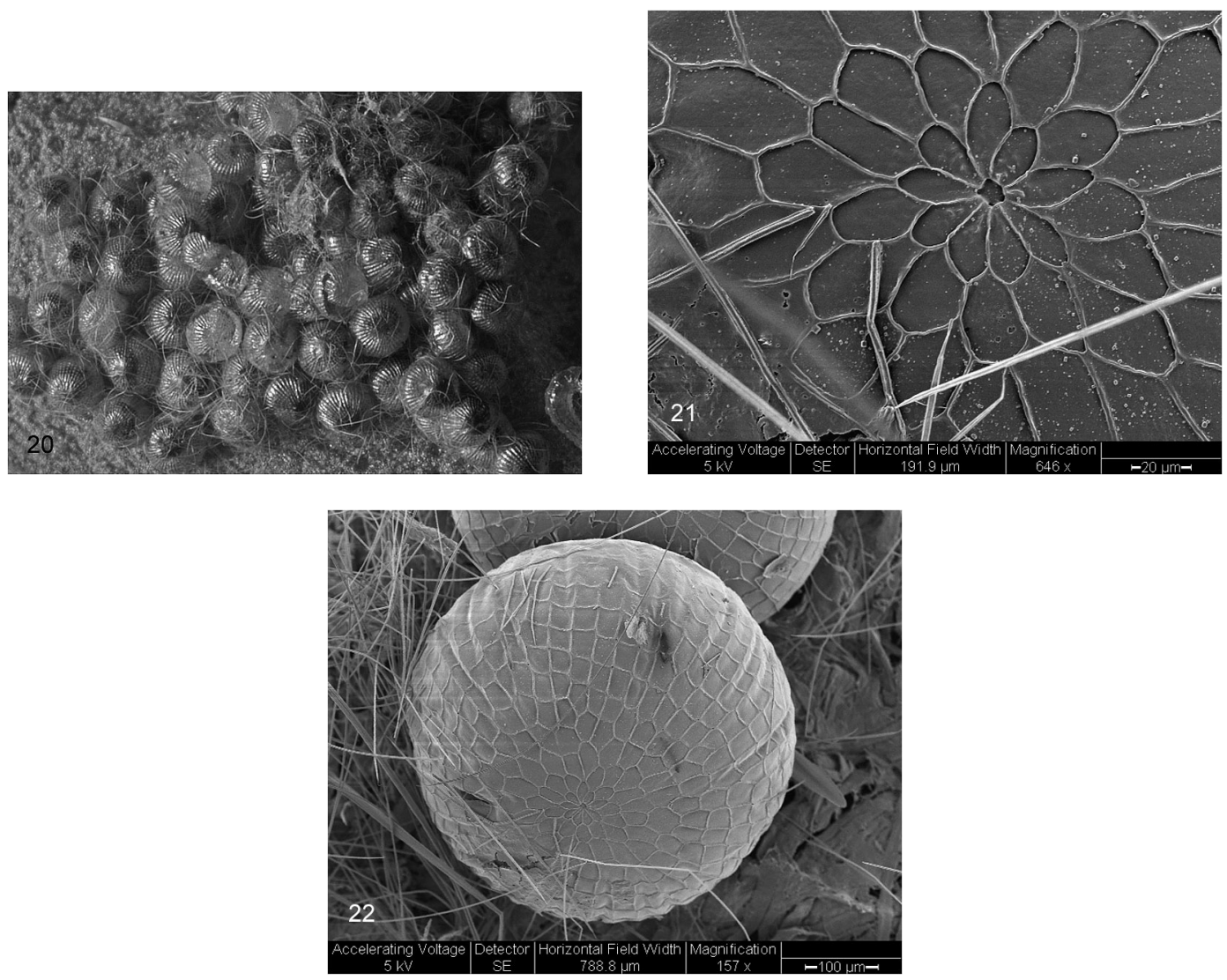

Figs 20-22. Images of Spodoptera exigua (Noctuidae) eggs: 20, habitus; 21, SEM image of the micropylar region; 22, overall SEM.

reported, using the end-points of the first-order ribs and the distance of these from the micropylar rosette (Bernhardt \& Phillips 1985). However, Bernhardt \& Phillips (1985) did not provide specific information that allows a direct comparison to be made with the description given here for $H$. armigera. There is a possibility that $H$. armigera eggs may have higher numbers of micropylar rosette cells on average than $H$. zea, though the numbers of micropylar rosette cells for $H$. zea reported by Neunzig (1964) does overlap the range found here for $H$. armigera. A comparison of the numbers of ribs and micropylar rosette cells for each of the three species can be seen in Table 2. Clearly, future work is needed to examine whether $H$. armigera eggs can be separated from those of $H$. zea, or indeed $H$. viresecens.

Lacanobia oleracea eggs, while being difficult to distinguish from unicolourous $M$. brassicae eggs under stereomicroscopy, could be seen to be distinctly different from them when SEM micrographs were used. Mamestra brassicae had a micropylar rosette that was much more prominent than the cells in the micropylar zone whereas the reverse was true in $L$. oleracea. For both species, the numbers of first-order ribs reported here are outside the ranges of published work using light microscopy (Döring 1955), but this may be due to the increased resolution of the SEM enabling better distinction to be made between first and second-order ribs, as the total number of ribs is comparable. The number of first-order ribs in $M$. brassicae observed using SEM micrographs is comparable with previous work (Sannino \& Espinosa 1999). Other species of Noctuidae have bicoloured eggs, for example Phlogophora meticulosa (Linnaeus, 1758) (Brooks 1991), and thus colouration alone should not be used as a basis for identifying $M$. brassicae eggs.

Spodoptera exigua could be easily separated from S. littoralis and S. litura with SEM images due to the presence of tubercles in the micropylar rosette cells, and the higher number of these cells. The tubercles inside the micropylar rosette cells are also depicted 
Table 2. Comparison of the number of selected surface features on the eggs of nine species of Noctuidae, including variation within species between different studies.

\begin{tabular}{lcccl}
\hline Species & No. of cells in micropylar rosette & No. of first-order ribs & Total no. ribs & Source \\
\hline Autographa gamma & $5-8$ & $13-18$ & $26-35$ & Current study \\
A. gamma & - & $28-30$ & $36-38$ & Döring (1955) \\
Helicoverpa armigera & $15-19$ & $13-15$ & $28-33$ & Current study \\
H. armigera & - & $13^{\mathrm{a}}$ & $27^{\mathrm{a}}$ & Matthews (1999) \\
Helicoverpa zea & - & - & $24-30$ & Barber (1941) \\
H. zea & $10-16$ & $11-17$ & $21-31$ & Neunzig (1964) \\
H. zea & - & - & $23-25$ & Peterson (1964) \\
Heliothis virescens & $10-16$ & $8-12$ & $18-25$ & Neunzig (1964) \\
H. virescens & - & - & $22-24$ & Peterson (1964) \\
H. virescens & $13-15$ & $10-11$ & $20-22$ & Fehrenbach et al. (1987) \\
Lacanobia oleracea & $12-16$ & $15-17$ & $38-47$ & Current study \\
L. oleracea & $13-15$ & $20-22$ & $41-46$ & Döring (1955) \\
Mamestra brassicae & $12-14$ & $18-21$ & $36-43$ & Current study \\
M. brassicae & 12 & $12-14$ & $32-38$ & Döring (1955) \\
M. brassicae & $11-14$ & $14-19$ & $34-40$ & Sannino \& Espinosa (1999) \\
Spodoptera exigua & $11-15$ & - & $41-50$ & Current study \\
S. exigua & - & - & $48-50$ & Peterson (1964) \\
S. exigua & 11 & - & - & Skudlik et al. (2005) \\
Spodoptera littoralis & $7-8$ & - & $45-50$ & Current study \\
S. littoralis & $6-11$ & - & $52-60$ & Fehrenbach et al. (1987) \\
Spodoptera litura & $8-9$ & - & $40-45$ & Current study, origin Thailand \\
S. litura & $8-9$ & - & $47-52$ & Current study, origin India \\
S. litura & $8-11$ & $44-46$ & Current study, origin unknown \\
\hline & & & &
\end{tabular}

${ }^{a}$ Counted from a published SEM micrograph.

in a published SEM micrograph of $S$. exigua (Skudlik et al. 2005). Spodoptera littoralis and S. litura eggs were morphologically similar, but consistent characters were found that could be used to separate the two species, though it is recognised that only limited populations were examined, especially of $S$. littoralis. It is more difficult to identify an isolated specimen using the cell shape character in the absence of reference micrographs, as the character is best used comparatively. This appears to be the first comparative study of the eggs of these two species, and no surface structural differences between the species have been previously described. Previous SEM micrographs of S. littoralis eggs (Fehrenbach 1987) show a higher total number of ribs than the current study, with the maximum number of ribs observed here being less than the minimum number of ribs previously described. However, only one population of S. littoralis was examined in each study and the differences could be variation between populations. The eggs of $S$. litura showed high variation in the number of ribs in the current study, with the culture population originating from India having more ribs on the eggs, and no overlap in ranges, when compared to the other two populations. Many species of Spodoptera appear to have morphologically similar eggs. Using light microscopy, four species of Spodoptera were described as resembling each other, all with hair strands cover- ing the egg masses (Peterson 1964). For S. frugiperda (Smith \& Abbot, 1797), SEM micrographs are available (Salkeld 1984) and the eggs are described as turquoise in colour, with 9-10 micropylar rosette cells which are the same height as the surrounding cells, and 58 ribs. However, using this information, S. frugiperda and S. littoralis were not considered to be separable (Fehrenbach 1987). The eggs of S. eridania were described as light green, with 10 micropylar rosette cells and 40-44 ribs (Valverde 2007); eggs of $S$. cosmioides had 7 micropylar rosette cells and 37-40 ribs (Zenker et al. 2007b). However, neither Valverde (2007) nor Zenker et al. (2007b) provided specific information that allows a direct comparison with the descriptions given here for $S$. littoralis and $S$. litura. Again, it is clear that future work is needed to examine the extent of variation between the eggs of Spodoptera species, as well as examining more populations of the species covered here to establish the variation within species.

Eggs can change colour considerably in the course of their development, for example in $M$. brassicae where strongly contrasted pigmented markings appear between laying and hatching of the egg. As the chorion is translucent, when the egg is close to hatching, all species may show the developing head capsule of the larva as a dark spot inside the egg, and even details of the larval setae may be visible; when viewed 
at a lower magnification, the entire egg may appear dark grey. Eggs stored in $70 \%$ ethanol rapidly lose their natural colouration and may darken, but the surface sculpturing is unaffected.

Many of the species studied here have wide geographic distributions and, as only limited numbers of populations could be studied here, the variation of egg morphology within species could not be assessed. Comparisons within species (Table 2) suggest that the total number of ribs may fall within a relatively narrow range within a given population, but that there is less consistency between populations. The numbers of micropylar rosette cells are more constant, though also subject to variation. However, where information is available, the micropylar rosette cell numbers reported here fall within the ranges of previous authors. One specimen of $S$. litura had two more micropylar rosette cells than any of the other specimens examined, which suggests that occasional individuals in a population may deviate from the ranges stated here. It was also outside the scope of this study to investigate the variation in eggs between females, though an attempt was made to examine different egg batches from rearing cages containing more than one female. No difference was seen between the egg batches of the Indian population of $S$. litura (sourced from one female), and eggs from the other two populations where there were at least 5 females.

The Noctuidae is a very large and diverse family, and this study covers only seven species. They were selected as being the species most commonly found during UK plant health inspections, but even in this context, many other species are found. The eggs of other Noctuidae may be misidentified using the keys presented here, especially if using only stereomicroscopy. While SEM is less available than stereomicroscopy or light microscopy, and more time consuming, the chance of misidentification using this technique would be lower due to the increased resolution and hence the fine chorion structures that can be examined. If time and resources permit, it is always good practice to confirm egg identifications by another method, whether SEM, molecular analysis, or rearing to late instar larvae or adult.

This work supports the conclusions of other authors (including Bernhardt \& Phillips 1985; Olivares \& Angulo 2004; Andaur-Arenas \& Olivares 2009), in finding that eggs of many species of moth in the family Noctuidae can be separated on the basis of surface structures on the chorion, including closely related species in the same genus. The value of SEM micrographs in enabling very fine structures to be seen with the high resolutions available when using this technique was clear. Olivares et al. (2005) and Fehrenbach et al. (1987) also used the number and form of the aeropyles, which were not considered in this study, and these may provide potentially useful extra characters to separate eggs in future work.

\section{Acknowledgements}

The Centre of Ecology and Hydrolology (Oxford), the Insect Supply Unit (Fera) and several Plant Health and Seeds Inspectors all kindly provided experimental material. The Plant Health Division of Defra funded this work, and it was carried out under the authority of several relevant annual Plant Health Licenses. I would like to thank David Crossley (Fera) for the macrophotographs of eggs.

\section{References}

Andaur-Arenas, D. \& T. Olivares, 2009. Ultraestructura de huevos en cinco especies de macrolepidópteros con una clave de los huevos de Copitarsia Hampson (Lepidoptera, Ditrysia). - Agrociencia 43: 49-59.

Barber, G.W., 1941. Observations on the egg and newly hatched larva of the corn ear worm on corn silk. Journal of Economic Entomology 34: 451-456.

Bernhardt, J.L. \& J.R. Phillips, 1985. Identification of eggs of the bollworm, Heliothis zea (Boddie), and the tobacco budworm, Heliothis virescens (F.). - Southwestern Entomologist 10: 236-238.

Brooks, M., 1991. A Complete Guide to British Moths. Jonathan Cape Ltd., London, 248 pp.

Döring, E., 1955. Zur Morphologie der Schmetterlingseir. - Akademie-Verlag, Berlin, 154 pp.

Fehrenbach, H., V. Dittrich \& D. Zissler, 1987. Eggshell fine structure of three lepidopteran pests: Cydia pomonella (L.) (Tortricidae), Heliothis virescens (Fabr.), and Spodoptera littoralis (Boisd.) (Noctuidae). - International Journal of Insect Morphology and Embryology 16: 201-219.

Hardwick, D.F., 1965. The corn earworm complex. Memoirs of the Entomological Society of Canada 40: $1-247$.

Hudson, A., 1973. Biosystematics in the genus Euxoa (Lepidoptera: Noctuidae). - Canadian Entomologist 105: 1199-1209.

Malumphy, C.M. \& J. Robinson, 2002. Lepidopterous larvae intercepted on imported produce of fresh bean, pea, okra, sweet pepper, aubergine and tomato fruit in England and Wales between 1970 and 2000. Entomologist's Gazette 53: 191-202.

Matthews, M., 1999. Heliothine Moths of Australia: A Guide to Pest Bollworms and Related Noctuid Groups. - CSIRO Publishing, 270 p.

Mochida, O., 1973. Two important insect pests, Spodoptera litura (F.) and S. littoralis (Boisd.) (Lepidoptera: Noctuidae), on various crops - morphological discrimination of the adult, pupal and larval stages. - Applied Entomology and Zoology 8: 205-214. 
Neunzig, H.H., 1964. The eggs and early-instar larvae of Heliothis zea and Heliothis virescens (Lepidoptera: Noctuidae). - Annals of the Entomological Society of America 57: 98-102.

Olivares, T.S. \& A. Angulo, 2004. Descripcion de los huevos de Copitarsia incommoda (Walker) y Copitarsia turbata (Herrich-Schaeffer) (Lepidoptera: Noctuidae: Cuculliinae). - Gayana 68: 112-116.

Olivares, T.S., S.A. Torres \& L.A. Zúñiga, 2005. Morfología de huevos de siete especies de nóctuidos de Chile (Lepidoptera: Noctuidae) y clave actualizada para su identificación. - Revista de Biología Tropical 53: 153-163.

Peterson, A., 1964. Egg types among moths of the Noctuidae (Lepidoptera). - Florida Entomologist 47: 71-91.

Salkeld, E.H., 1984. A catalogue of the eggs of some Canadian Noctuidae (Lepidoptera). - Memoirs of the Entomological Society of Canada 127: 1-167.

Sannino, L. \& B. Espinosa, 1999. Morphological notes on Mamestra brassicae (Lepidoptera Noctuidae). - Il Tabacco 7: 13-24.

Skinner, B., 1984. Colour Identification Guide to Moths of the British Isles. - Viking (Penguin Books Ltd), 267 pp.
Skudlik, J., I. Poprawa \& M.M. Rost, 2005. The egg capsule of Spodoptera exiqua Hübner, 1808 (Insecta, Lepidoptera, Noctuidae): morphology and ultrastructure. Zoologica Poloniae 50: 25-31.

Valverde, L., 2007. Microestructura del huevo de Spodoptera eridania (Stoll, 1782) (Lepidoptera: Noctuidae). - Acta Zoológica Lilloana 51: 53-56.

Waring, P. \& M. Townsend, 2003. Field Guide to the Moths of Great Britain and Ireland. - British Wildlife Publishing, 432 pp.

Zenker, M.M., I.S. Lima, A. Specht \& A.G. Duarte, 2007a. Caracterização morfológica dos imaturos de Hyponeuma taltula (Schaus) (Lepidoptera, Noctuidae, Herminiinae). - Revista Brasileira de Zoologia 24: 1101-1107.

Zenker, M.M., A. Specht \& E. Corseuil, 2007b. Estágios imaturos de Spodoptera cosmioides (Walker) (Lepidoptera, Noctuidae). - Revista Brasileira de Zoologia 24: 99-107.

Received: May 12, 2011

Accepted: May 7, 2012 